\title{
SPACE SCIENCE REVIEWS
}

VOLUME 13 Nos. 4, 5 and 6 SEPTEMBER, OCTOBER, NOVEMBER 1972

EDITORIAL COMMITTEE: W. J. G. BEYNON/C. DEJAGER/

J. ROEDERER

SPECIAL ISSUE

ULTRAVIOLET AND X-RAY SPECTROSCOPY

OF ASTROPHYSICAL AND LABORATORY PLASMAS

IAU Colloquium No. 14, held at Utrecht 24-26 August, 1971

Edited by A. H. GAB R IEL 


\section{SPACE SCIENCE REVIEWS}

Editorial Prof. W. J. G. Beynon, University College of Wales, Dept. of Physics, Committee: Penglais, Aberystwyth, Cards, Wales.

Main responsibility: The Earth's Neutral Atmosphere and Ionosphere.

Prof. C. de Jager, Space Research Laboratory of the Astronomical Institute, Beneluxlaan 21, Utrecht, The Netherlands.

Main responsibility: Astronomy.

Dr. S. I. Rasool, NASA, Goddard Institute for Space Studies, 2880 Broadway, New York, N.Y. 10025, U.S.A.

Prof. Juan G. Roederer, Dept. of Physics, Univ. of Denver, Denver, Colo. 80210, U.S.A.

Main responsibility: Magnetosphere and Interplanetary Matter.
Editorial S.-I. Akasofu, College, Alas.
A. P. Mitra, New Delhi
Board:
J.-E. Blamont, Verrières, France
J. E. Naugle, Washington, D. C.
R. L. F. Boyd, London
H. E. Newell, Washington, D. C.
L. Broglio, Rome
M. Nicolet, Brussels
M. Calvin, Berkeley, Calif.
T. Obayashi, Tokyo
R. R. Daniel, Bombay
B. J. O'Brien, Perth, Western
H. Friedman, Washington, D. C. Australia
L. Goldberg, Cambridge, Mass.
B. Peters, Lyngby, Denmark
W. N. Hess, Houston, Tex.
A. R. Hibbs, Pasadena, Calif.
Sir R. Peters, Cambridge, England
H. C. van de Hulst, Leyden
M. A. Pomerantz, Swarthmore, Pa.
G. H. Ludwig, Greenbelt, $M d$.
R. W. Porter, New York
R. Lüst, Garching-München
E. Rechtin, Washington, D.C.
G. J. F. MacDonald, Santa Barbara,
B. Rossi, Cambridge, Mass. Calif.
H. S. W. Massey, London
L. I. Sedov, Moscow
B. M. McCormac, Palo Alto, Calif.
J. A. Van Allen, Iowa City, Ia.
F. L. Whipple, Cambridge, Mass.
J. R. Winckler, Minneapolis, Minn.

Articles for publication should be sent to one of the members of the Editorial Committee.

Books for review should be sent to Prof. C. de Jager.

Published monthly, except in January, April and August. Subscription price per volume of 6 issues Dfl. 195,- (US \$63.38), including postage. About 9 issues will be published per year. Private persons (no institutes, laboratories, libraries, etc.) may subscribe at the reduced rate of Dfl. 75 ,--(US \$ 24.38) per volume, including postage. They should declare that the subscription is for their own personal use, that it will not replace any existing library subscription and will not be put at the disposal of any library. Subscriptions should be sent to the publisher, D. Reidel Publishing Company, P. O. Box 17, Dordrecht-Holland, or to any subscription agent. Private subscriptions should be sent direct to the publisher.

For advertisement rates apply to the publisher.

Copyright 1972 by D. Reidel Publishing Company, Dordrecht-Holland. All Rights Reserved.

Printed in The Netherlands by D. Reidel, Dordrecht. 
SPACE SCIENCE REVIEWS

Volume 13 Nos. 4, 5 and 61972 


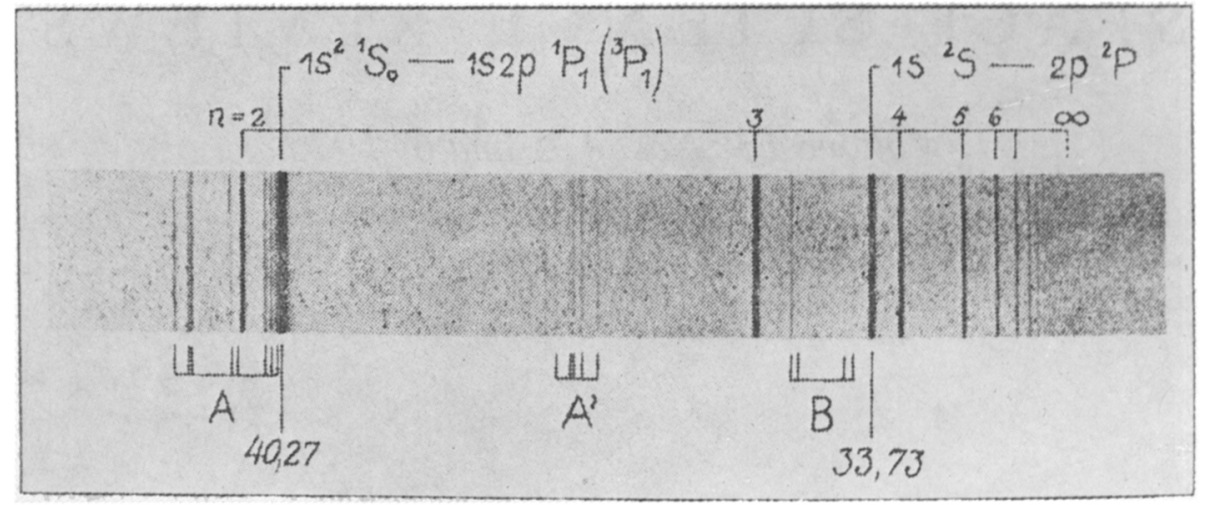

SATELLITE LINES IN THE SOFT X-RAY REGION

This spectrum was reported by Edlén and Tyrén in 1939 (Nature 143, 940) and shows for the first time weak satellites on the long wavelength side of resonance lines in a vacuum spark spectrum of carbon. Such features have been the subject of a renewed interest in the last few years (see Paper 4.1), since they are seen also in the solar spectrum, where they can be shown to be produced by the mechanism of dielectronic recombination.

(Reproduced by permission of the Editor of Nature.) 